\title{
Floristic study of Mt. Namdeogyu
}

\author{
Dong-Hyuk Lee, Dong-Pil Jin, Jung-Hyun Lee, In-Su Choi and Byoung-Hee Choi*
}

Department of Biological Sciences, Inha University, Incheon 402-751, Korea

(Received 4 December 2012; Revised 20 February 2013; Accepted 2 March 2013)

\section{남덕유산의 식물상}

\author{
이동혁 · 진동필 · 이정현 · 최인수 · 최병희* \\ 인하대학교 자연과학대학 생명과학과
}

\begin{abstract}
We investigated the flora of Mt. Namdeogyu, southern regions of Deogyusan National Park, from April of 2011 to September of 2012. The number of vascular plants in this area were summarized as 507 taxa, including 102 families, 296 genera, 444 species, 8 subspecies, 49 varieties, 6 forms. Among the recorded taxa, Korean endemic plants were 9 species and the floristic regional indicator plants were 80 taxa including 3 taxa in grade V, 3 taxa in grade IV, 19 taxa in grade III category. The rare and endangered plants which was designated by Korea Forest Service were 15 taxa comprising 1 endangered species (EN) of Rhododendron tschonoskii, 5 taxa of vulnerable (VU) such as Cynanchum inamoenum, Lilium cernuum, Gastrodia elata, Bupleurum euphorbioides, Paeonia japonica, and 9 least concerned (LC). In addition, the subalpine plants of the region were summarized as 24 taxa, and Mt. Deogyu area inclunding the Mt. Namdeogyu was suggested as the north most limits line of the distribution for 2 taxa, Abies koreana and Rhododendron tschonoskii, and as the south most limit of the distribution for Bupleurum euphorbioides.
\end{abstract}

Keywords: Deogyusan National Park, flora, Mt. Namdeogyu, subalpine plant, vascular plants

적 요: 덕유산국립공원 남부에 위치한 남덕유산일대의 관속식물상을 조사하였다. 현지조사는 2011년 4월부 터 2012년 9월까지 총 19회에 걸쳐 이루어졌으며, 조사 결과 남덕유산지역의 관속식물은 102과 296속 444종 8 아종 49변종 6품종 507분류군이었다. 이중에서 한국특산식물은 9종이 확인되었으며, 식물구계학적 특정식 물로는 $\mathrm{V}$ 등급 3 분류군, IV등급 3 분류군, III등급 19 분류군 등 총 80 분류군이 조사되었다. 산림청 지정 희귀 식물은 위기종 $(\mathrm{EN})$ 에 흰참꽃 1 종, 취약종 $(\mathrm{VU})$ 에 선백미꽃, 솔나리, 천마, 등대시호, 백작약 등 5 분류군, 약관 심종(LC)에 9 분류군 등 총 15 분류군이 확인되었다. 또한 남덕유산에 자생하는 아고산식물은 24 분류군으로 확인되었으며, 이 중에서 구상나무와 흰참꽃은 남덕유산을 포함한 덕유산지역이 분포의 최북단이고, 등대시 호는 분포의 최남단이었다.

주요어: 덕유산국립공원, 식물상, 남덕유산, 아고산식물, 관속식물

덕유산국립공원은 지리산, 가야산 등과 함께 남부지역 을 대표하는 산으로 백두대간의 끝자락에 위치한다. 향적 봉 $(1,614 \mathrm{~m})$ 을 중심으로 하여 북쪽으로는 적상산 $(1,029 \mathrm{~m})$,

\footnotetext{
*Author for correspondence: bhchoi@inha.ac.kr

http://www.pltaxa.or.kr

Copyright $(2013$ the Korean Society of Plant Taxonomists
}

거칠봉 $(1,178 \mathrm{~m})$ 및 설천봉 $(1,510 \mathrm{~m})$ 을 포함하고, 남쪽으 로는 남덕유산 $(1,507 \mathrm{~m})$ 과 무룡산 $(1,492 \mathrm{~m})$ 등을 포함하고 있으며, 1975년 231,650 km²의 면적에 대해 국내에서 10 번 째 국립공원으로 지정되었다. 하지만 덕유산국립공원내 에는 스키장을 포함하여 케이블카, 종합레져시설 등이 건 설되어, 이에 따른 등산객 및 행락객들의 증가로 일부 지 역의 산림이 크게 훼손되고 있다(Kim et al., 2010). 덕유산 
국립공원은 남방계식물의 북방한계선 또는 북방계식물 의 남방한계선이 되는 특이지역에 해당하며(Park et al., 2005), 특히 향적봉, 중봉 및 남덕유산 등의 산정부위에서 는 구상나무, 산오이풀, 솔나리 등의 식물들이 분포하는 아고산대 식생이 나타난다. 이러한 식물들은 대부분 과거 빙하기에 남하한 후, 기온이 상승함에 따라 산정부위로 밀려나 살아남은 종들로 기후와 같은 환경적인 변화에 민 감하여 기후온난화에 크게 위협받을 것으로 판단된다. 이 에 따라 최근 덕유산 향적봉과 중봉을 중심으로 기후변화 취약식물종의 식물계절성 변화에 대한 연구가 수행되었 다(Kim et al., 2011).

덕유산국립공원지역에 대한 식물상은 Yook and Ahn (1972)에 의해 덕유산 일대의 360여종에 대한 자원식물상 이 보고된 것을 비롯하여 Kim (1986)은 덕유산국립공원내 적상산에 관한 연구에서 391종류를 보고하면서 주변 산과 식물종구성 차이를 비교하여 논하였다. 이후 Kil and Kim (1994)은 덕유산의 소산식물 목록과 함께 생활형을 구분 하여 110 과 385 속 673 종 112 변종 10 품종의 총 795 분류군 을 보고하였고, Yim et al. (1994)은 541분류군을, Sun and Park (1999)은 환경부 제 2차 전국자연환경조사에서 덕유 산일대의 식물상을 395 분류군으로 보고하였다. 또한 최 근 덕유산국립공원 자연자원조사(Kim and Kim, 2004)에 서는 북부지역과 남부지역을 나누어 조사하였으며, 설천 봉 이하의 남부지역에서 96 과 302속 491종 1아종 73변종 7 품종의 총 572분류군을 보고하였다. 또한 Lim et al. (2004) 에 의하여 91 과 243속의 411분류군이 확인되었으며, Park et al. (2005)에 의해 90과 281속 549분류군의 식물목록과
함께 이들의 유용도가 보고된 바 있다. 이외에 덕유산국립 공원의 식생에 관한 연구가 다양하게 이루어졌다(Moon, 2001; Kim et al., 2010; Kim et al., 2011). 이와 같이 덕유산 국립공원에 대한 많은 선행조사가 이루어져 왔으나 지금 까지의 조사는 주봉인 향적봉 부근을 중심으로 한 식물상 조사 및 식생조사가 주로 이루어졌으며, 이외의 지역, 특 히 남덕유산에 대한 조사는 부족하다.

남덕유산은 덕유산국립공원 남부에 위치한 산지로, 관 광시설이 발달한 향적봉 및 적상산 일대에 비해 비교적 식생이 잘 보존된 지역이다. 또한 남덕유산 $(1,507 \mathrm{~m})$ 은 덕 유산국립공원내에서 고도가 세 번째(향적봉, $1,614 \mathrm{~m}$; 설 천봉, $1,510 \mathrm{~m}$ )로 높은 지역으로, 정상부에는 흰참꽃, 솔체 꽃 등 아고산식물들이 다수 분포하고 있다. 최근 남덕유 산의 활엽수림을 중심으로 한 식생연구(Kim et al., 2009) 가 수행된 바 있지만 남덕유산 일대의 식물상 조사는 미 흡한 실정이다.

따라서 본 연구에서는 연구가 부족한 남덕유산지역을 중심으로 관속식물상을 조사하고자 한다. 이와 함께 남덕 유산 아고산대에 분포하는 종구성과 분포를 파악함으로 서 기후변화에 취약한 이들의 보전관리를 위한 기초자료 를 제공하고자 한다.

\section{재료 및 방법}

\section{1. 조사지역 개황}

덕유산국립공원은 행정구역상 전라북도 무주군, 장수 군과 경상남도 거창군, 함양군, 2 개 도와 4 개 군에 걸쳐 위

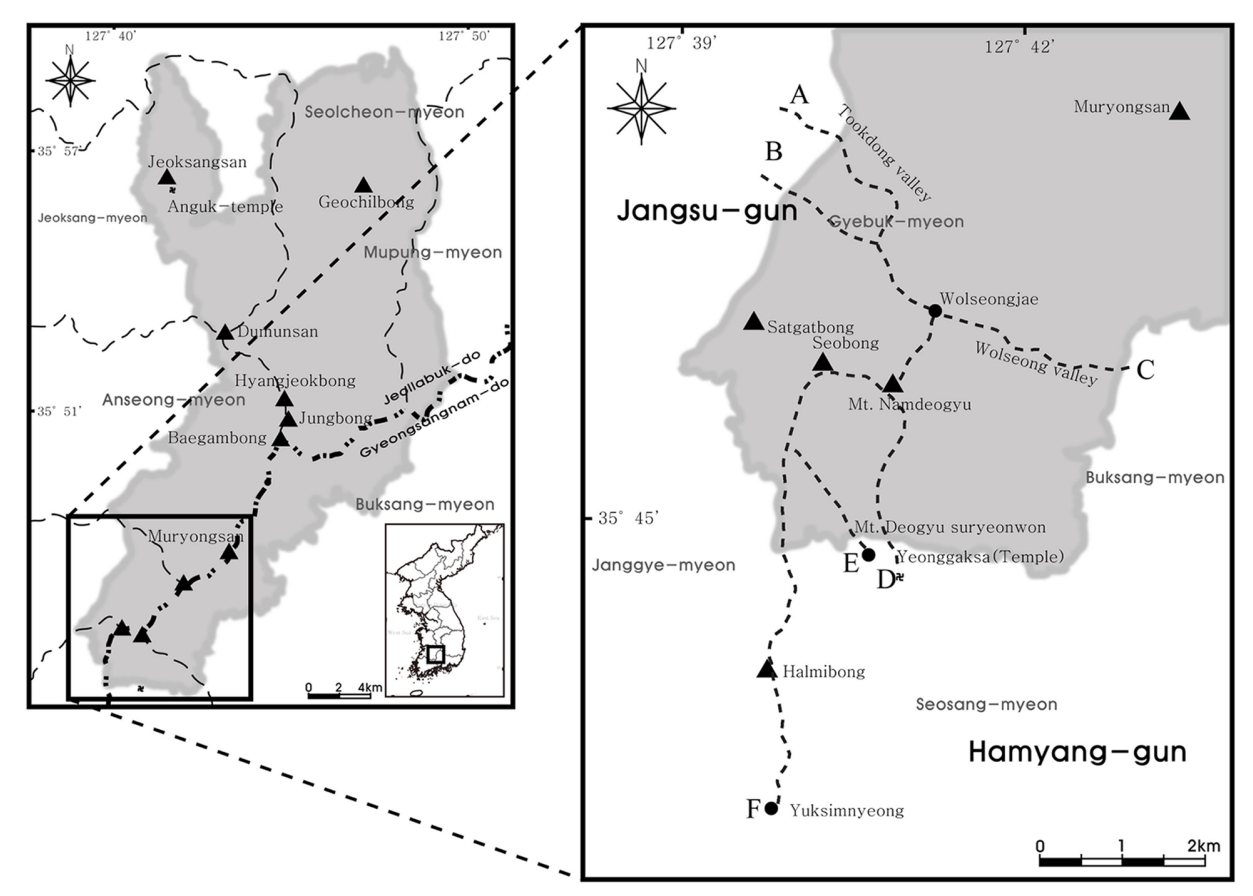

Fig. 1. Map of investigated area in this study. A-F, showing the routes of investigation. 
치하고 있으며, 지리적으로 동경 $127^{\circ} 40^{\prime} \sim 127^{\circ} 49^{\prime}$, 북위 $35^{\circ} 48^{\prime} \sim 36^{\circ} 59^{\prime}$ 에 위치하고 백두대간 내 소백산맥 줄기 의 소백산과 지리산의 중간에 위치한다(Fig. 1). 동쪽으로 는 가야산 $(1,430 \mathrm{~m})$, 서쪽으로는 내장산 $(763 \mathrm{~m})$, 운장산 $(1,126 \mathrm{~m})$, 남쪽의 백운산 $(1,218 \mathrm{~m})$ 과 지리산 $(1,915 \mathrm{~m})$, 북 쪽으로는 계룡산 $(845 \mathrm{~m})$ 과 속리산 $(1,058 \mathrm{~m})$ 으로 둘러싸인 산지지형에 위치하고 있다. 식물구계학적으로 남부아구 에 속하며(Lee and Yim, 1978), 식물군계로는 냉온대 중부 와 냉온대 남부에 걸쳐서 위치함으로써(Yim, 1977), 남방 계식물의 북방한계선 또는 북방계식물의 남방한계선이 되는 특이지역에 해당한다(Park et al., 2005). 남덕유산 은 남북으로 길게 이어진 덕유산국립공원의 남쪽에 위치 하고, 고도에 따라 다양한 식생분포를 보이며 월성계곡 및 토옥동계곡과 같은 계곡부와 산 정상부의 암벽지대 등 다양한 생육환경이 존재한다.

\section{2. 조사방법}

남덕유산 일대의 관속식물상을 파악하기 위해 남덕유 산 정상부와 서봉지역에 대하여 2011년 4월부터 2012년 9 월까지 개화기와 결실기를 중심으로 총 19회의 현지조사 를 실시하였다(Table 1). 재료는 꽃과 열매 등의 생식기관 이 있는 개체를 우선적으로 수집하였다. 수집된 표본은 Lee (1996), Lee (2003), Lee (2006), Park (2009) 등의 도감을 이용하여 동정하였고, 학명은 The Genera of Vascular Plants of Korea (Flora of Korean Editorial Committee, 2007)에 따라 표기하였다. 또한 각 분류군별로 전문가의 검수를 실시하 여 종목록에 대한 정확성을 높이고자 하였다. 조사된 목 록 중 양치식물은 Smith et al. (2006), 나자식물은 Engler (Melchior, 1964), 피자식물은 Cronquist (1981)의 분류체계 에 따라 배열하였으며, 과 이하는 학명의 알파벳순으로 정리하였고 식재된 것으로 판단되는 종의 경우에는 (재) 표시를 하여 구분하였다. 수집된 식물은 석엽표본으로 제 작하여, 인하대학교 식물표본실(IUI)에 보관하였으며, 일 부는 국립수목원 $(\mathrm{KH})$ 과 국립생물자원관 $(\mathrm{KB})$ 에 보관되 었다.

\section{결과 및 고찰}

\section{1. 식물상}

본 연구를 통해 남덕유산 일대의 관속식물은 102 과 296 속 444종 8아종 49변종 6품종 507분류군으로 확인되었다 (Appendix 1, 2). 본 연구에서 분포가 확인된 507분류군은 선행연구에서 보고된 연구결과, Yook and Ahn (1972) 360 분류군, Kim (1986) 391분류군, Kil and Kim (1994) 795분 류군, Park et al. (2005) 549분류군 등과 차이를 나타낸다. 이러한 차이는 기존의 연구가 덕유산 전 지역에 대해 이 루어진 반면, 금번조사는 남덕유산 위주로 이루어졌으며, 조사경로의 차이 등에서 비롯된 것으로 판단된다.

남덕유산의 수직적 고도에 따른 식물의 분포를 보면
$800 \mathrm{~m}$ 까지 구간에는 주로 소나무가 넓은 지역에 걸쳐 분 포한다. 교목층으로는 층층나무, 산딸나무, 산벚나무, 물 푸레나무, 관목층으로는 병꽃나무, 싸리, 생강나무, 노린 재나무, 초본층으로는 짚신나물, 가락지나물, 산박하, 단 풍취, 참취, 맑은대쑥 등이 흔하게 나타났고, 토옥동계곡 과 월성계곡에서는 계곡을 따라서 키버들 및 떡버들, 물 참대와 까치박달, 층층나무 등이 주로 확인되었다. 한편

Table 1. Dates and routes of the investigations. The symbols of route are corresponding to those of Fig. 1.

\begin{tabular}{lcc}
\hline \hline No. & \multicolumn{1}{c}{ Date } & \multicolumn{1}{c}{ Investigation routes } \\
\hline 1 & 15 Apr. 2011 & E: Mt. Deogyu suryeonwon $\rightarrow$ Seobong \\
& & D: Around Younggaksa (Temple) \\
& A: Around Tookdong valley
\end{tabular}

209 May 2011 D: Around Younggaksa (Temple)

326 May 2011 A: Tookdong valley $\rightarrow$ Wolseongjae

427 May 2011 D: Younggaksa (Temple) $\rightarrow$ Mt. Namdeogyu

515 Jun. 2011 D: Around Younggaksa (Temple)

C: Wolseong valley $\rightarrow$ Mt. Namdeogyu

F: Yuksimnyeong $\rightarrow$ Halmibong

6 16 Jul. 2011 E: Mt. Deogyu suryeonwon $\rightarrow$ Mt. Namdeogyu

7 17 Jul. 2011 C: Wolseong valley $\rightarrow$ Wolseongjae

A: Tookdong valley $\rightarrow$ Wolseongjae

811 Aug. 2011 C: Wolseong valley $\rightarrow$ Mt. Namdeogyu

912 Aug. 2011 E: Mt. Deogyu suryeonwon $\rightarrow$ Mt. Namdeogyu D: Younggaksa (Temple) $\rightarrow$ Mt. Namdeogyu

1025 Aug. 2011 D: Around Younggaksa (Temple)

$\mathrm{C}$ : Wolseong valley $\rightarrow$ Wolseongjae

F: Yuksimnyeong $\rightarrow$ Seobong $\rightarrow$ Mt. Deogyu

A: Tookdong valley $\rightarrow$ Wolseongjae

1115 Sep. 2011 C: Wolseong valley $\rightarrow$ Wolseongjae

A: Tookdong valley $\rightarrow$ Wolseongjae

1216 Sep. 2011 D: Younggaksa (Temple) $\rightarrow$ Mt. Namdeogyu

1307 Oct. 2011 D: Younggaksa (Temple) $\rightarrow$ Mt. Namdeogyu

1408 Oct. 2011 A: Around Tookdong valley

C: Around Wolseong valley

1528 Apr. 2012 A: Tookdong valley $\rightarrow$ Wolseongjae

B: Around Satgatbong

1615 Jun. 2012 D: Younggaksa (Temple) $\rightarrow$ Mt. Namdeogyu

$\mathrm{C}$ : Wolseong valley $\rightarrow$ Wolseongjae

1714 Jul. 2012 B: Around Satgatbong

1805 Aug. 2012 E: Mt. Deogyu $\rightarrow$ Mt. Namdeogyu

C: Wolseong valley $\rightarrow$ Wolseongjae

1913 Sep. 2012 B: Around Satgatbong 
Table 2. List of rare and endangered plants in Mt. Namdeogyu area.

\begin{tabular}{|c|c|c|c|}
\hline No. & Family & Scientific name & Degree \\
\hline 1 & Ericaceae & Rhododendron tschonoskii Maxim. 흰참꽃 & EN \\
\hline 2 & Asclepiadaceae & Cynanchum inamoenum (Maxim.) Loes. 선백미꽃 & \\
\hline 3 & Liliaceae & Lilium cernuum Kom. 솔나리 & \\
\hline 4 & Orchidaceae & Gastrodia elata Blume 천마 & VU \\
\hline 5 & Paeoniaceae & Paeonia japonica (Makino) Miyabe \& Takeda 백작약 & \\
\hline 6 & Umbelliferae & Bupleurum euphorbioides Nakai 등대시호 & \\
\hline 7 & Boraginaceae & Trigonotis icumae (Maxim.) Makino 덩굴꽃마리 & \\
\hline 8 & Gentianaceae & Gentiana triflora f. japonica (Kusn.) H. Hara 과남풀 & \\
\hline 9 & Liliaceae & Lilium distichum Nakai ex Kamib. 말나리 & \\
\hline 10 & Liliaceae & Maianthemum dilatatum (Wood) A. Nelson \& J.F. Macbr. 큰두루미꽃 & \\
\hline 11 & Liliaceae & Streptopus ovalis (Ohwi) F.T. Wang \& Y.C. Tang 금강애기나리 & $\mathrm{LC}$ \\
\hline 12 & Ophioglossaceae & Botrychium virginianum (L.) Sw. 늦고사리삼 & \\
\hline 13 & Pinaceae & Abies koreana E.H. Wilson 구상나무 & \\
\hline 14 & Ranunculaceae & Clematis koreana Kom. 세잎종덩굴 & \\
\hline 15 & Violaceae & Viola albida Palib. 태백제비꽃 & \\
\hline
\end{tabular}

Table 3. List of 5th to 3rd grade taxa of specially designated plants by phytogeographical distribution of Mt. Namdeogyu area.

\begin{tabular}{|c|c|c|c|}
\hline No. & Family & Scientific name & Degree \\
\hline 1 & Liliaceae & Lilium cernuum Kom. 솔나리 & \\
\hline 2 & Orchidaceae & Gastrodia elata Blume 천마 & $\mathrm{V}$ \\
\hline 3 & Umbelliferae & Bupleurum euphorbioides Nakai 등대시호 & \\
\hline 4 & Aceraceae & Acer pictum var. mono Thunb. 고로쇠나무 & \\
\hline 5 & Ericaceae & Rhododendron tschonoskii Maxim. 흰참꽃 & IV \\
\hline 6 & Saxifragaceae & Chrysosplenium ramosum Maxim. 가지괭이눈 & \\
\hline 7 & Aceraceae & Acer komarovii Pojark. 시닥나무 & \\
\hline 8 & Aceraceae & Acer palmatum Thunb. 단풍나무 & \\
\hline 9 & Asclepiadaceae & Cynanchum inamoenum (Maxim.) Loes. 선백미꽃 & \\
\hline 10 & Asteraceae & Cirsium setidens (Dunn) Nakai 고려엉겅퀴 & \\
\hline 11 & Cyperaceae & Carex gifuensis Franch. 애기감둥사초 & \\
\hline 12 & Dipsacaceae & Scabiosa tschiliensis Grning 솔체꽃 & \\
\hline 13 & Ericaceae & Vaccinium hirtum var. koreanum (Nakai) Kitam. 산앵도나무 & \\
\hline 14 & Poaceae & Diarrhena fauriei (Hack.) Ohwi 광릉용수염풀 & \\
\hline 15 & Labiatae & Glechoma grandis (A. Gray) Kuprian. 긴병꽃풀 & \\
\hline 16 & Liliaceae & Maianthemum dilatatum (Wood) A. Nelson \& J.F. Macbr. 큰두루미꽃 & III \\
\hline 17 & Pinaceae & Abies koreana E.H. Wilson 구상나무 & \\
\hline 18 & Ranunculaceae & Aconitum longecassidatum Nakai 흰진범 & \\
\hline 19 & Rosaceae & Sanguisorba hakusanensis Makino 산오이풀 & \\
\hline 20 & Rosaceae & Spiraea fritschiana Schneid. 참조팝나무 & \\
\hline 21 & Rubiaceae & Asperula lasiantha Nakai 갈퀴아재비 & \\
\hline 22 & Rubiaceae & Asperula odorata L. 선갈퀴 & \\
\hline 23 & Theaceae & Stewartia pseudocamellia Maxim. 노각나무 & \\
\hline 24 & Ulmaceae & Ulmus davidiana Planch. 당느릅나무 & \\
\hline 25 & Apiaceae & Angelica gigas Nakai 참당귀 & \\
\hline
\end{tabular}


영각사 주변에는 개비자나무가 군락을 이루고 있으며, 경 작지를 중심으로 큰금계국, 코스모스, 돼지풀, 토끼풀 등 다수의 귀화식물이 나타났다. 800 1,200 $\mathrm{m}$ 의 구간에서는 신갈나무, 갈참나무와 같은 참나무속 식물들이 넓게 분포 하였고, 관목으로는 서어나무, 단풍나무, 병꽃나무, 초본 으로는 큰개현삼, 모시대, 조릿대, 투구꽃, 풀솜대, 꽃며느 리밥풀, 맑은대쑥, 넓은잎외잎쑥, 짚신나물, 산박하, 왜모 시풀 등이 주로 나타났다. 고도 $1,200 \mathrm{~m}$ 이상에서는 교목 층의 개체수가 점차 줄어들어 관목 및 초본식물들이 우세 하게 나타난다. 또한 산 정상부에서는 암벽지대가 나타나 며 능선을 따라서 흰참꽃, 산철쭉, 미역줄나무 등의 관목 이 주로 나타나며 초본으로는 돌양지꽃, 산오이풀, 동자꽃, 처녀치마, 범꼬리 등이 나타났다.

\section{2. 특정식물종}

특산식물: 특산식물은 한정된 지역에서만 생육하는 식 물을 말한다(Lee and Yim, 2002). 최근 발표된 Oh et al. (2005)의 특산식물목록에 따르면, 남덕유산에서 자생하 는 한반도 특산식물은 고려엉겅퀴, 노각나무, 병꽃나무, 각시서덜취, 나래완두, 구상나무, 외대으아리, 할미밀망, 갈퀴아재비 등 9종으로 확인되었다. 이는 확인된 남덕유 산 관속식물 507 분류군의 $1.8 \%$ 에 해당한다. 한편 기존연 구에서 보고된 12분류군(Yim et al., 1994), 22분류군(Lim et al., 2004), 25분류군(Park et al., 2005) 등과는 다소 차이를 보이는데 이는 조사지역의 차이와 함께 분류학적인 처리 및 본 조사에서 종만을 대상으로 한 차이로 해석된다. 구 상나무는 남덕유산 정상부에서 서봉으로 이어지는 능선 에 주로 분포하였다. 나래완두는 덕유산 수련원에서 서봉 으로 이어지는 등산로 중 계곡 주변부에 군락을 이루어 생육하는 것이 확인되었다.

희귀 및 멸종위기식물: 본 조사지역에서 확인된 식물 중 IUCN 평가기준에 따라 수목원에서 제시한 희귀식물 분류군(Korea National Arboretum, 2008)은 세잎종덩굴, 말 나리, 과남풀 등 15 분류군으로 확인되었다. 등급별로 보 면, 위기종(EN)은 흰참꽃 1종, 취약종(VU)은 선백미꽃, 솔 나리, 천마, 등대시호, 백작약 5분류군, 약관심종(LC)은 태 백제비꽃, 금강애기나리 덩굴꽃마리, 과남풀, 말나리, 큰 두루미꽃, 금강애기나리, 늦고사리삼, 구상나무, 세잎종 덩굴, 태백제비꽃 9분류군으로 나타났으며, 이러한 결과 는 남덕유산 지역에서 확인된 분류군의 약 $3.0 \%$ 에 해당한 다(Table 2). 흰참꽃은 남덕유산 정상 암벽지대에 여러 개 체가 생육하고 있는 것을 확인하였으며 생육상태는 비교 적 양호한 것으로 판단된다. 솔나리는 이번 조사를 통해 남덕유산 정상부근과 서봉 지역의 바위틈에서 약 30 여 개 체가 자생하고 있는 것을 확인하였으며, 백작약은 토옥동 계곡 교목림에서 몇 개체가 확인되었다. 세잎종덩굴은 남 덕유산 정상에서 서봉으로 이어지는 능선에서 소수의 개
체가 나타났다. 하지만 기존연구(Lim et al., 2004)를 통해 남덕유산에서 향적봉으로 이어지는 능선에서 자생하는 것으로 기록된 누른종덩굴은 이번조사에서 확인하지 못 하였다. 본 종에 대해 학자에 따라 세잎종덩굴의 이명 또 는 변종으로 취급하기도 하며, 오동정의 가능성이 있으므 로 추가적인 조사를 통해 이에 대한 분포의 재검토가 요 구된다.

식물구계학적 특정식물종: 남덕유산 일대에 자생하는 식물 중 환경부에서 지정한 식물구계학적 특정종(Ministry of Environment, 2006)은 5등급에 솔나리, 천마, 등대시호 등 3 분류군, 4 등급에 고로쇠나무, 흰참꽃, 가지괭이눈 등 3 분류군, 3 등급에 시닥나무, 선백미꽃, 긴병꽃풀 등 19 분류 군, 2 등급에 큰참나물, 백작약, 처녀치마 등 27 분류군, 1 등 급에 노랑물봉선, 개비자나무, 범꼬리 등 28 분류군, 총 80 분류군이었다(Table 3). 천마는 5등급종으로 국내에서 는 전국적으로 분포하지만 약재로서의 가치로 인해 불 법남획으로 그 개체수가 줄어들고 있다(Korea National Arboretum, 2008). 이번 조사에서는 월성계곡과 덕유산수 련원에서 서봉에 이르는 구간의 다소 습한 지역에서 나타 났다. 자생지가 등산로에서 멀리 떨어져 있어, 남획의 위 험은 적지만 소수 개체만 확인되어 피압 등에 의해 개체 군이 사라질 것이 우려되며, 효과적인 자생지의 크기를 유지 할 수 있는 대책이 요구된다. 솔체꽃은 3 등급종으로 국내에서는 제주도 한라산을 포함하여 주로 중부이북 높 은 산지의 초지대에서 자생하는 초본으로 조사지역내에 서는 서봉일대 암석이 발달한 초지대에서 수개체가 확인 되었다.

귀화식물: 귀화식물은 좀명아주, 개망초, 돼지풀, 망초, 서양민들레, 지느러미엉겅퀴, 코스모스, 큰금계국, 둥근 잎나팔꽃, 오리새, 토끼풀, 붉은토끼풀, 달맞이꽃, 돌소리 쟁이, 총 7 과 14 분류군이 확인되었으며, 국화과 식물이 7 분류군으로 가장 높은 비율을 나타냈다. 귀화율(귀화식물 의 종류수/출현식물의 전 종류수 $\times 100)$ 은 약 $2.6 \%$ 로 우리 나라 산지의 평균귀화율(4.4\%) (Kim et al., 2000)보다 낮게 나타나 비교적 산림이 잘 보존되어 있는 것으로 판단된다. 조사지역 내에서 귀화식물은 주로 토옥동 계곡 및 영각사 주변의 저지대에서 확인되었다. 이것은 인근에 마을과 경 작지가 위치해 사람들의 출입이 잦아짐에 따라 이로 인한 유입이 원인으로 판단된다.

\section{3. 남덕유산 아고산대 식물}

남덕유산에서 확인된 고산식물: 국내 분포하는 고산식 물에 대하여 여러 학자들에 의해 연구 되었지만 학자들마 다 정의하는 분류군들은 다소 차이를 보인다(Chung, 1989; Kong and Watts, 1993; Lee, 2000). 본 연구에서는 Chung (1989)과 Kong and Watts (1993)이 제시한 목록을 기준으로 
Table 4. The list of sub-alpine plants in Mt. Namdeogyu area.

\begin{tabular}{|c|c|c|c|c|c|}
\hline No. & Family & Scientific name & Chung (1989) & Kong \& Watts (1993) & Present record \\
\hline 1 & Aceraceae & Acer komarovii Pojark. 시닥나무 & O & & \\
\hline 2 & Betulaceae & Betula ermanii Cham. 사스래나무 & O & 0 & \\
\hline 3 & Celastraceae & Tripterygium regelii Sprague \& Takeda 미역줄나무 & 0 & & \\
\hline 4 & Compositae & Ligularia fischeri (Ledeb.) Turcz. 곰취 & & ○ & \\
\hline 5 & Crassulaceae & Meterostachys sikokianus (Makino) Nakai 난쟁이바위솔 & & & $\bigcirc$ \\
\hline 6 & Dipsacaceae & Scabiosa tschiliensis Grning 솔체꽃 & & & $\bigcirc$ \\
\hline 7 & Ericaceae & Rhododendron tschonoskii Maxim. 흰참꽃 & 0 & & \\
\hline 8 & Gentianaceae & Gentiana triflora f. japonica (Kusn.) H. Hara 과남풀 & 0 & & \\
\hline 9 & Liliaceae & Lilium cernuum Kom. 솔나리 & & & $\bigcirc$ \\
\hline 10 & Liliaceae & Streptopus ovalis (Ohwi) F.T. Wang \& Y.C. Tang 금강애기나리 & & & $\bigcirc$ \\
\hline 11 & Lycopodiaceae & Lycopodium serratum Thunb. 뱀톱 & & & $\bigcirc$ \\
\hline 12 & Lycopodiaceae & Lycopodium chinense Christ 다람쥐꼬리 & & & $\bigcirc$ \\
\hline 13 & Pinaceae & Abies koreana E.H. Wilson 구상나무 & & 0 & \\
\hline 14 & Polygonaceae & Bistorta manshuriensis (Petrov ex Kom.) Kom. 범꼬리 & 0 & & \\
\hline 15 & Primulaceae & Primula jesoana Miq. 큰앵초 & & & $\bigcirc$ \\
\hline 16 & Ranunculaceae & Clematis koreana Kom. 세잎종덩굴 & ○ & ○ & \\
\hline 17 & Rosaceae & Potentilla dickinsii Franch. \& Sav. 돌양지꽃 & ○ & & \\
\hline 18 & Rosaceae & Sanguisorba hakusanensis Makino 산오이풀 & ○ & ○ & \\
\hline 19 & Rosaceae & Sorbus commixta Hedl. 마가목 & & 0 & \\
\hline 20 & Rosaceae & Rosa suavis Willd. 인가목 & ○ & & \\
\hline 21 & Rosaceae & Aruncus dioicus var. kamtschaticus (Maxim.) H. Hara 눈개승마 & & & $\bigcirc$ \\
\hline 22 & Saxifragaceae & Saxifraga oblongifolia Nakai 참바위취 & 0 & & \\
\hline 23 & Scrophulariaceae & Pedicularis resupinata f. albiflora (Nakai) W.T. Lee 흰송이풀 & & & $\bigcirc$ \\
\hline \multirow[t]{2}{*}{24} & Apiaceae & Bupleurum euphorbioides Nakai 등대시호 & 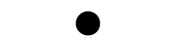 & & \\
\hline & & & 12 & 6 & 9 \\
\hline
\end{tabular}

: present survey and recorded in literatures $\bigcirc$ : present survey and not recorded in literatures

정리하였으며, 그 결과 각각 25분류군(Chung, 1989), 17분 류군(Kong and Watts, 1993), 총 37분류군으로 나타났다. 하 지만 조밥나물, 장대나물, 광대나물 등은 저지대에서도 흔하게 나타나며 고도에 따라 연속적으로 분포하는 종으 로 이번 결과에서는 제외하였다. 또한 솔나리, 솔체꽃 등 9 분류군은 Chung (1989)과 Kong and Watts (1993)의 기준에 는 포함되어 있지는 않지만 이들의 분포는 주로 산 정상
부 및 고산지대에서 나타나는 식물로서 이번 조사결과에 포함하였다. 이를 종합하면 남덕유산에는 19과 23속 21종 2 변종 1 품종, 총 24 분류군의 아고산식물들이 분포하는 것 으로 확인되었다(Table 4). 이들의 분포는 주로 서봉과 남 덕유산 정상부 및 월성재로 이어지는 능선의 암벽지대에 서 나타났다. 이 구간은 관목 및 초본층으로 이루어진 아 고산대의 식생이 나타나는데, 고도는 높지 않지만 암석지
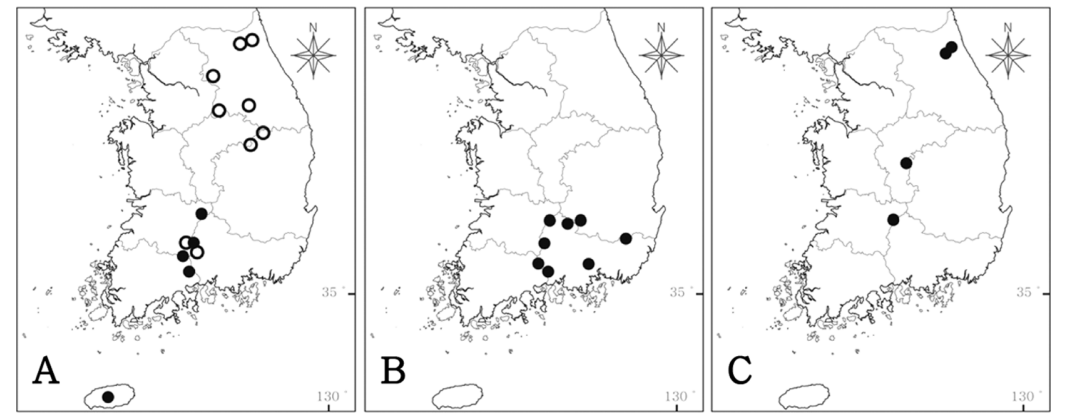

Fig. 2. Distribution map of some plants in Mt. Namdeogyu area. A. Abies koreana E.H.Wilson( $(\mathbf{)})$ and Abies nephrolepis Maixm.( () ; B. Rhododendron tschonoskii Maxim.; C. Bupleurum euphorbioides Nakai. 
대로 이루어진 정상부에 부는 바람 등의 환경적 요인에 의해 범꼬리, 산오이풀같은 고산식물들의 분포가 유지되 고 있는 것으로 판단된다. 특히 이러한 종들은 환경적인 영향에 민감하여 최근 기후온난화와 같은 환경변화에 취 약할 것으로 보이며, 남덕유산의 경우 집단의 크기가 작 고 등산로와 인접해 있어 등산객들에 의한 답압 및 남획 에 의한 자생지의 훼손가능성이 크다. 이에 대해 Kong (2007)은 백두대간의 아고산대에 있는 등산로에 의한 식 생과 토양의 피해를 줄이기 위해 주요 산지 정상일대에 대한 자연휴식년제의 도입, 정상일대를 우회하는 샛길, 또는 등산로의 폭을 줄이고 나무데크 등의 보호시설 설치 와 같은 대책의 도입을 제시한 바 있다. 남덕유산의 경우, 일부구간에서 이러한 시설이 마련되어 있지만, 남덕유산 정상 일대에 대한 보호시설 설치를 검토함으로서 아고산 식물 집단의 자생지 훼손을 최소화할 수 있을 것으로 판 단된다.

남덕유산이 분포한계인 식물: 고산식물중 남덕유산이 분포의 경계에 위치하는 분류군으로는 구상나무, 등대시 호, 흰참꽃 등 3 분류군으로 확인되었다(Fig. 2). 구상나무 와 흰참꽃은 한반도 남부지역의 고산지역에 분포하는 종 으로 남덕유산을 포함한 덕유산일대가 가야산과 함께 분 포의 최북단으로 나타나지만(Fig. $2 \mathrm{~A}, \mathrm{~B})$, 이들의 분포를 보았을 때 유입역사는 상이할 것으로 판단된다. 구상나무 는 한반도 특산식물로 지리산과 덕유산 일대 산정상부에 분포하고, 제주도 한라산에 군락을 이루고 있다(Lee and Yim, 2002). 분비나무와 같은 근연분류군과는 구과의 포 의 특징에 의해 구분된다. 하지만 구과가 없을때는 구분 이 어려우며, Chang et al. (1997)은 구상나무와 분비나무가 혼재되어 나타나는 덕유산과 지리산집단의 경우, 잡종현 상이 폭넓게 일어나는 것으로 확인하였다. 이후 Kong et al. (2006)은 한반도에 분포하는 소나무과 식물들의 생물지리 학적 연구에서 과거 기후변동에 의해 한반도 남부지방까 지 남하한 분비나무가 북상하지 못하고 남부 아고산대에 고립되어 한반도 고유종인 구상나무로 분화한 것으로 보 았다. 흰참꽃은 한국 및 사할린지역과 일본 전역의 높은 산지에 분포하는 종으로 국내에서는 남부지역에 국한되 어 분포하며 이번 조사에서는 남덕유산 정상일대에서 확 인되었다.

등대시호는 전세계적으로 한반도, 중국 동북부(Jirin) 및 러시아(Ussuri) 지역에 분포하는 만주구계식물로, 남덕유 산의 자생지는 분포의 최남단에 해당한다(Fig. 2C). 등대 시호는 국내에서는 주로 강원도 설악산 일대에 큰 군락을 이루고, 충북 속리산 등지에 분포하며, 이번 조사에서는 남덕유산 정상부에서 수십 개체가 확인되었다. 국내 자생 지의 경우, 집단 간의 거리가 멀고 일부 산정에만 고립되 어 분포하고 있다. 특히 남덕유산 자생지는 분포의 최남 단에 위치하여 그 중요성이 더 크다고 할 수 있어, 이들의
개체수를 유지할 수 있도록 지속적인 모니터링과 함께 보 호조치가 요구된다.

\section{사 사}

본 연구는 2012년도 산림청의 ‘우리 식물의 주권확보 (CBD 등)을 위한 기반연구'(과제번호: S111111L040000) 및 국립수목원 한반도 산림생물표본인프라 고도화 사업 (KNA1-1-5, 11-2)의 지원과 환경부 국립환경과학원에서 수행하는 2012년도 전국자연환경조사의 일환으로 수행 되었습니다.

\section{인용문헌}

Chang, J. S., J. I. Jeon and J. O. Hyun. 1997. An analysis of morphological variation in Abies koreana Wilson and A. nephrolepis (Traut.) Maxim. of Korea (Pinaceae) and their phylogenetic problems. Journal of Korean Forest Society 86: 378-390. (in Korean)

Chung, Y. H. 1989. Distribution pattern of alpine plants in South Korea. Proceedings of the College of Natural Science of Seoul National University 14: 67-81. (in Korean)

Cronquist, A. 1981. An Integrated System of Classification of Flowering Plants. Columbia University Press, New York.

Kil, B. S. and C. H. Kim. 1994. The flora of Toggyusan National Park, Korea. Journal of Wonkwang University 28: 63-100. (in Korean)

Kim, H. J., J. K. Hong, S. C. Kim, S. H. Oh and J. H. Kim. 2011. Plant phenology of threatened species for climate change in sub-alpine zone of Korea. Korean Journal of Plant Resources 24: 549-556. (in Korean)

Kim, H. S., S. M. Lee, H. L. Chung and H. K. Song. 2009. A study of the vegetation in the Deogyusan National Parkfocused on the forest vegetation of the Namdeogyu area. Korean Journal of Environment and Ecology 23: 471-484. (in Korean)

Kim, H. S., S. M. Lee and H. K. Song. 2010. An analysis of the vegetation on the southern and northern slopes in the Deogyusan National Park. Korean Journal of Environment and Ecology 24: 601-610. (in Korean)

Kim, H. S., S. M. Lee and H. K. Song. 2011. Actual vegetation distribution status and ecological succession in the Deogyusan National Park. Korean Journal of Environment and Ecology 25: 37-46. (in Korean)

Kim, I. T. and H. J. Kim. 2004. Flora. In Report of Natural Resources in Deogyusan National Park. Korea National Park Service, Seoul. Pp. 127-205. (in Korean)

Kim, J. M., Y. J. Yim and E. S. Jeon. 2000. Naturalized Plants of 
Korea. Science Books, Seoul. (in Korean)

Kim, M. Y. 1986. A study on the flora of Mt. Jeoksang. Jeonbuk National University Basic Science 9: 105-125. (in Korean)

Kong, W. S. and D. Watts. 1993. The Plant Geography of Korea. Kluwer Academic Publishers, The Netherlands.

Kong, W. S. 2006. Biogeography of native Korean Pinaceae. Journal of Korean Geographical Society 41: 71-93. (in Korean)

Kong, W. S. 2007. Biogeography of Korean Plants. Geobook, Seoul. (in Korean)

Korea National Arboretum. 2008. Rare Plants Data Book in Korea. Korea National Arboretum, Pocheon. (in Korean)

Lee, T. B. 2003. Coloured Flora of Korea. Hyangmunsa, Seoul. (in Korean)

Lee, W. T. 1996. Standard Illustrations of Korean Plants. Academy Publishing Co., Seoul. (in Korean)

Lee, W. T. and Y. J. Yim. 1978. Studies on the distribution of vascular plants in the Korean Peninsula. Korean Journal Plant Taxonomy 8(Appendix): 1-33. (in Korean)

Lee, W. T. and Y. J. Yim. 2002. Plant Geography. Kangwon National University Press, Chuncheon. (in Korean)

Lee, Y. N. 2000. Alpine Flowers of Korea. Kyohak Publishing Co., Seoul. (in Korean)

Lee, Y. N. 2006. New Flora of Korea. Kyohaksa, Seoul. (in Korean)

Lim, D. O., Y. S. Kim, Y. K. Park, Y. M. Ryu and M. H. Koh. 2004. Vascular plant of Mt. Deog-yu area in the Baekdudaegan. Korean Journal of Environment and Ecology 18: 107122. (in Korean)

Melchior, H. 1964. An Engler's Syllabus der Pflanzenfamilien, band II. Gebruder Borntraeger, Berlin-Nikolasse.
Ministry of Environment. 2006. A Guide to the 3rd National Natural Environment Research. Ministry of Environment. Pp. 114-155. (in Korean)

Moon, H. S. 2001. Studies on the forest vegetation structure in subalpine zone of Mt. Deokyu National Park. Journal of Agriculture and Life Sciences 35: 47-54. (in Korean)

Oh, B. U., D. G. Jo, K. S. Kim and C. G. Jang. 2005. Endemic Vascular Plants in the Korean Peninsula. Korea National Arboretum, Pocheon. (in Korean)

Park, K. W., Y. H. Kwon, K. Choi, S. H. Oh, D. K. Kim, J. H. Tho, K. H. Tae and J. H. Kim. 2005. A floristic study on economic plants of Deogyusan National Park area. Korean Journal of Plant Resources. 18: 32-56. (in Korean)

Park, S. H. 2009. New Illustrations and Photographs of Naturalized Plants of Korea. Ilchokak, Seoul. (in Korean)

Sun, B. Y. and J. H. Park. 1999. Flora of Deogyusan (Muju, Geochang). 2nd National Nature Environment Research. Ministry of Environment. Pp. 130-163. (in Korean)

Smith, A. R., K. M. Pryer, E. Schuettpelz, P. Korall, H. Schneider and P. G. Wolf. 2006. A classification for extant ferns. Taxon 55: 705-731.

Yim, K. B., Y. S. Kim, S. H. Chun and J. I. Jeon. 1994. Floristic study on Tǒkyusan National Park. Korean Journal of Environment and Ecology 7: 91-103. (in Korean)

Yim, Y. J. 1977. Distribution of forest vegetation and climate in Korean Peninsula. IV. Zonal distribution of forest vegetation in relation to thermal climate. Japanese Journal of Ecology 27: 269-278.

Yook, C. S. and D. K. Ahn. 1972. The medical plants of Mt. Deokyu. Korean Journal of Pharmacognosy 3: 217-225. (in Korean) 
Appendix 1. List of the vascular plants of Mt Namdeogyu. The complete plant lists including voucher numbers are uploaded in the homepage of The Korean Society of Plant Taxonomists (http://www.pltaxa.or.kr).

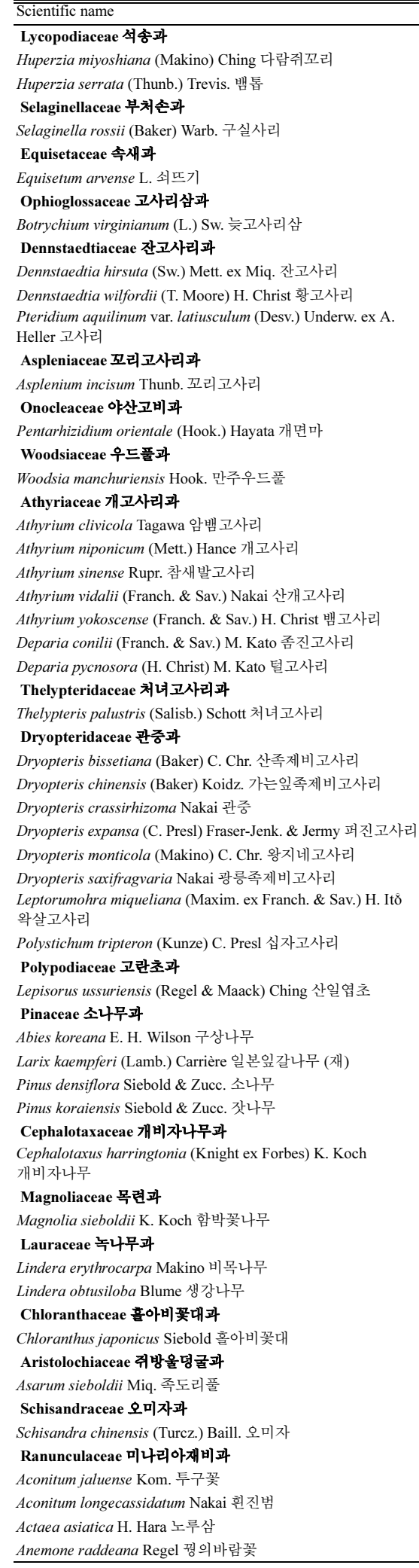

\section{Cimicifuga dahurica (Turcz, ex Fisch. \& C. A. Mey.) Maxim.}

눈빛승마

Clematis apiifolia DC. 사위질빵

Clematis brachyura Maxim. 외대으아리

Clematis koreana Kom. 세잎종덩굴

Clematis patens $\mathrm{C}$. Morren \& Decne. 큰꽃으아리

Clematis trichotoma Nakai 할미밀망

Hepatica asiatica Nakai 노루귀

Pulsatilla cernua var. koreana (Yabe ex Nakai) U. C. La 할미 곳

Ranunculus japonicus Thunb. 미나리아재비

Thalictrum acteaifolium var. brevistylum Nakai 은뀡의다리

Thalictrum aquilegifolium var. sibiricum Regel \& Tiling 뀡의다리

Thalictrum tuberiferum Maxim. 산꿩의다리

Lardizabalaceae 으름덩굴과

Akebia quinata (Thunb.) Decne. 으름덩굴

Menispermaceae 새모래덩굴과

Cocculus trilobus (Thunb.) DC. 댕댕이덩굴

Papaveraceae 양귀비과

Chelidonium majus var. asiaticum (H. Hara) Ohwi 애기똥풀

Fumariaceae 현호색과

Corydalis pauciovulata Ohwi 선괴불주머니

Corydalis remota Fisch. ex Maxim. 현호색

Corydalis speciosa Maxim. 산괴불주머니

Ulmaceae 느릅나무과

Ulmus davidiana Planch. in DC. 당느릅나무

Ulmus davidiana var. japonica (Rehder) Nakai 느릅나무

Cannabaceae 삼과

Humulus japonicus Siebold \& Zucc. 환삼덩굴

Moraceae 뽕나무과

Broussonetia papyrifera (L.) L'Her. ex Vent. 꾸지나무

Morus bombycis Koidz. 산뽕나무

\section{Urticaceae 쐐기풀과}

Boehmeria longispica Steud. 왜모시풀

Boehmeria platanifolia Franch. \& Sav. 개모시풀

Boehmeria spicata (Thunb.) Thunb. 좀깨잎나무

Boehmeria tricuspis (Hance) Makino 거북꼬리

Laportea bulbifera (Siebold \& Zucc.) Wedd. 혹쐐기풀

Pilea peploides (Gaudich.) Hook. \& Arn. 물통이

Fagaceae 참나무과

Castanea crenata Siebold \& Zucc. 밤나무 (재)

Quercus $\times$ urticaefolia Blume 갈졸참나무

Quercus aliena Blume 갈참나무

Quercus dentata Thunb. in Murray 떡갈나무

Quercus mongolica Fisch. ex Ledeb. 신갈나무

Quercus serrata Murray 졸참나무

Ouercus variabilis Blume 굴참나무

Betulaceae 자작나무과

Alnus firma Siebold \& Zucc. 사방오리 (재)

Alnus japonica (Thunb.) Steud. 오리나무

Betula ermanii Cham. 사스래나무

Betula schmidtii Regel 박달나무

Carpinus cordata Blume 까치박달

Corylus heterophylla Fisch. ex Travtv. 난티잎개암나무

Corylus sieboldiana Blume 참개암나무

Chenopodiaceae 명아주과

Chenopodium album var. centrorubrum Makino 명아주

Chenopodium ficifolium $\mathrm{Sm}$. 좀명아주

Amaranthaceae 비름과

Achyranthes japonica (Miq.) Nakai 쇠무를

Portulacaceae 쇠비름과

Portulaca oleracea L. 쇠비름

Caryophyllaceae 석죽과

Cerastium holosteoides var. hallaisanense (Nakai) M. Mizush. 점나도나물

Cucubalus baccifer var. japonicus Miq. 덩굴별꽃

Lychnis cognata Maxim. 동자꽃

Pseudostellaria heterophylla (Miq.) Pax 개별꽃

Pseudostellaria palibiniana (Takeda) Ohwi 큰개별꽃

Silene firma Siebold \& Zucc. 장구체

Silene seoulensis Nakai 가는장구채

Stellaria alsine var. undulata (Thunb.) Ohwi 벼룩나물
Stellaria aquatica (L.) Scop, 쇠별꽃

Stellaria media (L.) Vill. 별꽃

Polygonaceae 마디풀과

Polygonum aviculare L. 마디풀

Polygonum dissitiflorum Hemsl. 가시여꾸

Polvgonum filiforme Thunb. 이삭여뀌

Polygonum lapathifolium L. 흰여뀌

Polygonum longisetum Bruijn 개여뀌

Polvgonum manshuriense Petrov ex Kom. 범꼬리

Polygonum nepalense Meisn. 산여뀌

Polygonum perfoliatum L. 며느리배꼽

Polygonum posumbu Buch.-Ham. ex D. Don 장대여뀌

Polygonum senticosum (Meisn.) Franch. \& Sav. 며느리밑씻개

Polygonum sagittatum var. sieboldii (Meisn.) Maxim. ex Kom. 미꾸리낚시

Polygonum thunbergii Siebold \& Zucc. 고마리

Polygonum viscoferum Makino 끈끈이여뀌

Polygonum viscoferum var. robustum Makino 큰끈끈이여뀌

Rumex acetosa $\mathrm{L}$. 수영

Rumex obtusifolius $\mathrm{L}$. 돌소리쟁이

Paeoniaceae 작약과

Paeonia japonica (Makino) Miyabe \& Takeda 백작약

Theaceae 차나무과

Stewartia koreana Nakai ex Rehder 노각나무

Actinidiaceae 다래나무과

Actinidia arguta (Siebold \& Zucc.) Planch. ex Miq. 다래

Actinidia polygama (Siebold \& Zucc.) Maxim. 개다래

Clusiaceae 물레나물과

Hypericum ascyron L. 물레나물

Hypericum erectum Thunb. 고추나물

Tiliaceae 피나무과

Corchoropsis tomentosa (Thunb.) Makino 수까치깨

Violaceae 제비꽃과

Viola acuminata Ledeb. 졸방제비꽃

Viola albida Palib. 태백제비꽃

Viola albida var. chaerophylloides (Regel) F. Maek. 남산제비꽃

Viola collina Besser 둥근털제비꽃

Viola japonica Langsd. ex Ging. 왜제비꽃

Viola keiskei Miq. 잔털제비꽃

Viola mandshurica W. Becker 제비꽃

Viola orientalis (Maxim.) W. Becker 노랑제비꽃

Viola rossii Hemsl. 고깔제비꽃

Viola selkirkii Pursh ex Goldie 뫼제비꽃

Viola tokubuchiana var. takedana (Makino) F. Maek.

민둥뫼제비꽃

Viola tokubuchiana var. takedana f. variegata $\mathrm{F}$. Maek.

줄민둥뫼제비꽃

Viola variegata Fisch. ex Link 알록제비꽃

Viola verecunda A. Gray 콩제비꽃

Salicaceae 버드나무과

Salix caprea L. 호랑버들

Salix koriyanagi Kimura ex Goerz 키버들

Brassicaceae 십자화과

Arabis gemmifera (Matsum.) Makino 산장대

Arabis glabra (L.) Bernh. 장대나물

Capsella bursa-pastoris (L.) Medik. 냉이

Cardamine fallax (O. E. Schulz) Nakai 좁쌀냉이

Cardamine flexuosa With. 황새냉이

Cardamine impatiens L. 싸리냉이

Cardamine leucantha (Tausch) O. E. Schulz 미나리냉이

Draba nemoros $\mathrm{L}$. 꽃다지

Rorippa indica (L.) Hiern 개갓냉이

Rorippa palustris (L.) Besser 속속이풀

\section{Ericaceae 진달래과}

Rhododendron mucronulatum Turcz. 진달래

Rhododendron schlippenbachii Maxim. 철쭉

Rhododendron tschonoskii Maxim. 흰참꽃

Rhododendron yedoense f. poukhanense (H. Lév.) M. Sugim. 산철쭉

Vaccinium hirtum var. koreanum (Nakai) Kitam. 산앵도나무

Vaccinium oldhamii Miq. 정금나무

Pyrolaceae 노루발과

Chimaphila japonica Miq. 매화노루발 


\begin{tabular}{|c|c|}
\hline Pyrola japonica Klenze ex Alef. 노루발 & Amorpha fruticosa L. 족제비싸리 \\
\hline Ebenaceae 감나무과 & Amphicarpaea bracteata subsp. edgeworthii (Benth.) H. Ohashi \\
\hline Diospyros lotus L. 고욤나무 & 새콩 \\
\hline Styracaceae 때죽나무과 & Chamaecrista nomame (Siebold) H. Ohashi 차풀 \\
\hline Styrax japonicus Siebold \& Zucc. 때죽나무 & $\begin{array}{l}\text { Desmodium podocarpum var. oxyphyllum (DC.) H. Ohashi } \\
\text { 도둑놈의갈고리 }\end{array}$ \\
\hline Styrax obassia Siebold \& Zucc. 쪽동백나무 & Glycine soja Siebold \& Zucc. 돌콩 \\
\hline Symplocaceae 노린재나무과 & Indigofera koreana Ohwi 좀땅비싸리 \\
\hline Symplocos sawafutagi Nagam. 노린재나무 & Kummerowia stipulacea (Maxim.) Makino 둥근매듭풀 \\
\hline Primulaceae 앵초과 & Kummerowia striata (Thunb.) Schindl. 매듭풀 \\
\hline Lysimachia clethroides Duby 큰까치수염 & Lespedeza bicolor Turcz. 싸리 \\
\hline Lysimachia japonica Thunb. 좀가지풀 & Lespedeza cuneata (Dum. Cours.) G. Don. 비수리 \\
\hline Hydrangeaceae 수국과 & Lespedeza inschanica (Maxim.) Schindl. 청비수리 \\
\hline Deutzia glabrata Kom. 물참대 & Lespedeza maximowiczii C. K. Schneid. 조록싸리 \\
\hline Deutzia parviflora Bunge 말발도리 & Maackia amurensis Rupr. \& Maxim. 다릅나무 \\
\hline Deutzia uniflora Shirai 매화말발도리 & Pueraria lobata (Willd.) Ohwi 칡 \\
\hline $\begin{array}{l}\text { Hydrangea serrata f. acuminata (Siebold \& Zucc.) E. H. Wilson } \\
\text { 사수국 }\end{array}$ & Robinia pseudoacacia L. 아까시나무 \\
\hline & Trifolium pratense L. 붉은토끼풀 \\
\hline Philadelphus schrenkii Rupr. 고광나무 & Trifolium repens L. 토끼풀 \\
\hline Philadelphus tenuifolius Rupr. ex Maxim. 얇은잎고광나무 & Vicia hirticalycina Nakai 나래완두 \\
\hline Grossulariaceae 까치밥나무과 & Vicia unijuga A. Braun 나비나물 \\
\hline Ribes mandshuricum (Maxim.) Kom. 까치밥나무 & Vigna angularis var. nipponensis (Ohwi) Ohwi \& H. Ohashi \\
\hline Crassulaceae 돌나물과 & 새팥 \\
\hline Meterostachys sikokianus (Makino) Nakai 난쟁이바위솔 & Vigna minima (Roxb.) Ohwi \& H. Ohashi 좀돌팥 \\
\hline Sedum aizoon $\mathrm{L}$. 가는기린초 & Elaeagnaceae 보리수나무과 \\
\hline Sedum bulbiferum Makino 말똥비름 & Elaeagnus umbellata Thunb. 보리수나무 \\
\hline Sedum oryzifolium Makino 땅채송화 & Onagraceae 바늘꽃과 \\
\hline Sedum polytrichoides Hemsl. 바위채송화 & Circaea alpina $\mathrm{L}$. 쥐털이슬 \\
\hline Sedum sarmentosum Bunge 돌나물 & $\begin{array}{l}\text { Circaea lutetiana subsp. quadrisulcata (Maxim.) Asch. \& } \\
\text { Magnus 말털이슬 }\end{array}$ \\
\hline Saxifragaceae 범의귀과 & $\begin{array}{l}\text { Magnus 발덜이를 } \\
\text { Circaea mollis Siebold \& Zucc. 털이슬 }\end{array}$ \\
\hline Astilbe rubra Hook. f. \& Thomson ex Hook. f. 노루오줌 & $\begin{array}{l}\text { Circaea molls Siebold \& Zucc. 닐이를 } \\
\text { Oenothera odorata Jacq. 달맞이꽃 }\end{array}$ \\
\hline Chrysosplenium flagelliferum F. Schmidt 애기괭이눈 & Alangiaceae 박쥐나무과 \\
\hline Chrysosplenium grayanum Maxim. 괭이눈 & Alangium platanifolium var. trilobum (Miq.) Ohwi 박쥐나무 \\
\hline $\begin{array}{l}\text { Chrysosplenium pilosum var. fulvum (N. Terracc.) Hara } \\
\text { 흰갱이눈 }\end{array}$ & 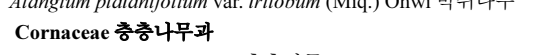 \\
\hline Chrysosplenium pilosum var. valdepilosum $\mathrm{Ohwi}$ 금괭이눈 & Cornus controversa Hemsl. 층층나무 \\
\hline Chrysosplenium ramosum Maxim. 가지괭이눈 & Cornus kousa F. Buerger ex Miq. 산딸나무 \\
\hline Deutzia crenata Siebold \& Zucc. 빈도리 & Santalaceae 단향과 \\
\hline $\begin{array}{l}\text { Saxifraga fortunei var. incisolobata (Engl. \& Irmsch.) Nakai } \\
\text { 바위떡풀 }\end{array}$ & $\begin{array}{l}\text { Thesium chinense Turcz. 제비꿀 } \\
\text { Celastraceae 노박덩굴과 }\end{array}$ \\
\hline Saxifraga oblongifolia Nakai 참바위취 & Celastrus orbiculatus Thunb. 노박덩굴 \\
\hline Saxifraga stolonifera Meerb. 바위취 & Euonymus bungeanus Maxim. 좀참빗살나무 \\
\hline Rosaceae 장미과 & Euonymus hamiltonianus Wall. 참빗살나무 \\
\hline Agrimonia coreana Nakai 산짚신나물 & Euonymus oxyphyllus Miq. 참회나무 \\
\hline Agrimonia pilosa Ledeb. 짚신나물 & Euonymus pauciflorus Maxim. 회목나무 \\
\hline Aria alnifolia (Siebold \& Zucc.) Decne. 팥배나무 & Euonymus sachalinensis (F. Schmidt) Maxim. 회나무 \\
\hline Aruncus dioicus var. kamtschaticus (Maxim.) H. Hara 눈개승마 & Euonymus trapococca Nakai 버들회나무 \\
\hline Crataegus pinnatifida Bunge 산사나무 & Tripterygium regelii Sprague \& Takeda 미역줄나무 \\
\hline Duchesnea chrysantha (Zoll. \& Moritzi) Miq. 뱀딸기 & Euphorbiaceae 대극과 \\
\hline Geum aleppicum Jacq. 큰뱀무 & Euphorbia sieboldiana C. Morren \& Decne. 개감수 \\
\hline Malus baccata $(\mathrm{L}$.$) Borkh. 야광나무$ & Phyllanthus ussuriensis Rupr. \& Maxim. 여우주머니 \\
\hline Potentilla anemonifolia Lehm. 가락지나물 & Securinega suffruticosa (Pall.) Rehder 광대싸리 \\
\hline Potentilla chinensis Ser. 딱지꽃 & Vitaceae 포도과 \\
\hline Potentilla dickinsii Franch. \& Sav. 돌양지 꽃 & Ampelopsis brevipedunculata (Maxim.) Trautv. 개머루 \\
\hline 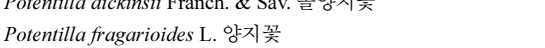 & Staphyleaceae 고추나무과 \\
\hline $\begin{array}{l}\text { Potentilla fragarioides } \mathrm{L} \text {. 양시 亲 } \\
\text { Potentilla yokusaiana Makino 민눈양지꽃 }\end{array}$ & Staphylea bumalda DC. 고추나무 \\
\hline $\begin{array}{l}\text { Potentilla yokusaiana Makino 민눈양지꽃 } \\
\text { Pourthiaea villosa (Thunb.) Decne. 윤노리나무 }\end{array}$ & Aceraceae 단풍나무과 \\
\hline $\begin{array}{l}\text { Pourthiaea villosa (Thunb.) Decne. 윤노리나무 } \\
\text { Prunus jamasakura Siebold ex Koidz. 벚나무 }\end{array}$ & Acer komarovii Pojark. 시닥나무 \\
\hline & Acer palmatum Thunb. in Murray 단풍나무 \\
\hline Prunus sargentii Rehder 산벚나무 & Acer pictum var. mono Thunb. 고로쇠나무 \\
\hline Rosa acicularis Lindl. 민둥인가목 & Acer pseudosieboldianum (Pax) Kom. 당단풍나무 \\
\hline Rosa multiflora Thunb. 찔레나무 & Acer tataricum subsp. ginnala (Maxim.) Wesm. 신나무 \\
\hline Rubus coreanus Miq. 복분자딸기 & Anacardiaceae 옻나무과 \\
\hline Rubus crataegifolius Bunge 산딸기 & Rhus javanica L. 붉나무 \\
\hline Rubus parvifolius L. 멍석딸기 & Toxicodendron trichocarpum (Miq.) Kuntze 개옻나무 \\
\hline Sanguisorba hakusanensis Makino 산오이풀 & Simaroubaceae 소태나무과 \\
\hline Sanguisorba officinalis L. 오이풀 & Ailanthus altissima (Mill.) Swingle 가중나무 \\
\hline Sorbus commixta Hedl. 마가목 & Rutaceae 운향과 \\
\hline Spiraea fritschiana C. K. Schneid. 참조팝나무 & Zanthoxylum schinifolium Siebold \& Zucc. 산초나무 \\
\hline Spiraea prunifolia var. simpliciflora (Nakai) Nakai 조팝나무 & Oxalidaceae 갱이밥과 \\
\hline Stephanandra incisa (Thunb.) Zabel 국수나무 & Oxalis corniculata L. 괭이밥 \\
\hline Fabaceae 콩과 & Oxalis obtriangulata Maxim. 큰괭이밥 \\
\hline Albizia julibrissin Durazz. 자귀나무 & Geraniaceae 쥐손이풀과 \\
\hline
\end{tabular}

Geranium thunbergii Siebold ex Lindl. \& Paxton 이질풀 Geranium wilfordii Maxim. 세잎쥐손이 Balsaminaceae 봉선화과

Impatiens noli-tangere $\mathrm{L}$. 노랑물봉선

Impatiens textori Miq. 물봉선

Araliaceae 두릅나무과

Aralia cordata var. continentalis (Kitag.) Y. C. Chu 독활 Apiaceae 미나리과

Angelica cartilaginomarginata (Makino ex Y. Yabe) Nakai 처녀바디

Angelica var. distans (Nakai) Kitag. 흰바디나물

Angelica decursiva (Miq.) Franch. \& Sav. 바디나물

Angelica gigas Nakai 참당귀

Angelica polymorpha Maxim. 궁궁이

Angelica tenuissima Nakai 고본

Anthriscus sylvestris (L.) Hoffm. 전호

Bupleurum euphorbioides Nakai 등대시호

Cryptotaenia japonica Hassk. 파드득나물

Cymopterus melanotilingia (H. Boissieu) C. Y. Yoon 큰참나물

Heracleum moellendorffii Hance 어수리

Hydrocotyle maritima Honda 선피막이

Osmorhiza aristata (Thunb.) Rydb. 긴사상자

Ostericum grosseserratum (Maxim.) Kitag. 신감채

Ostericum sieboldii (Miq.) Nakai 묏미나리

Peucedanum terebinthaceum (Fisch. ex Trevir.) Fisch. ex Turcz in DC. 기름나물

Pimpinella brachycarpa (Kom.) Nakai 참나물

Pleurospermum camtschaticum Hoffm. 왜우산풀

Sanicula chinensis Bunge 참반디

Torilis japonica (Houtt.) DC. 사상자

Gentianaceae 용담과

Gentiana triflora f. japonica W. T. Lee \& W. K. Paik 과남풀 Gentiana zollingeri Fawc. 큰구슬붕이

Asclepiadaceae 박주가리과

Cynanchum atratum Bunge 백미꽃

Cynanchum inamoenum (Maxim.) Loes. 선백미꽃

Metaplexis japonica (Thunb.) Makino 박주가리

Solanaceae 가지과

Solanum nigrum L. 까마중

Convolvulaceae 메꽃과

Cuscuta australis R. Br. 실새삼

Cuscuta japonica Choisy in Zoll. 새삼

Ipomoea purpurea (L.) Roth 둥근잎나팔꽃

Boraginaceae 지치과

Bothriospermum tenellum (Hornem.) Fisch. \& C. A. Mey. 꽃받이

Trigonotis icumae (Maxim.) Makino 덩굴꽃마리

Trigonotis peduncularis (Trevis.) Benth. ex Baker \& S. Moore 꽃마리

Verbenaceae 마편초과

Callicarpa japonica Thunb. 작살나무

Phrymaceae 파리풀과

Phryma leptostachya var. oblongifolia (Koidz.) Honda 파리풀

Lamiaceae 꿀풀과

Agastache rugosa (Fisch. \& C. A. Mey.) Kuntze 배초향

Clinopodium micranthum (Regel) H. Hara 두메층층이

Elsholtzia splendens Nakai ex F. Maek. 꽃향유

Glechoma grandis (A. Gray) Kuprian. 긴병꽃풀

Isodon inflexus (Thunb.) Kud 산박하

Isodon japonicus (Burm. f.) H. Hara 방아풀

Lamium album var. barbatum (Siebold \& Zucc.) Franch. \& Sav. 광대수염

Lamium amplexicaule L. 광대나물

Leonurus japonicus Houtt. 익모초

Leonurus macranthus Maxim. 송장풀

Lycopus lucidus Turcz. ex Benth. 쉽싸리

Meehania urticifolia (Miq.) Makino 벌깨덩굴

Mosla punctulata (J. F. Gmel.) Nakai 들깨풀

Prunella asiatica Nakai 꿀풀

Scutellaria pekinensis var. transitra (Makino) H. Hara ex H. W. $\mathrm{Li}$ 산골무꽃

Teucrium viscidum Blume 덩굴곽향

Plantaginaceae 질경이과 


\begin{tabular}{|c|}
\hline Plantago asiatica L. 질경이 \\
\hline Oleaceae 물푸레나무과 \\
\hline Forsythia koreana (Rehder) Nakai 개나리 (재) \\
\hline Fraxinus mandshurica Rupr. 들메나무 \\
\hline Fraxinus rhynchophylla Hance 물푸레나무 \\
\hline Fraxinus sieboldiana Blume 쇠물푸레 \\
\hline Ligustrum obtusifolium Siebold \& Zucc. 쥐똥나무 \\
\hline Syringa patula (Palib.) Nakai 털개회나무 \\
\hline Scrophylariaceae 현삼과 \\
\hline Mazus pumilus (Burm. f.) Steenis 주름잎 \\
\hline Melampyrum roseum Maxim. 꽃며느리밥풀 \\
\hline $\begin{array}{l}\text { Melampyrum roseum var. japonicum Franch. \& Sav. } \\
\text { 수염며느리밥풀 }\end{array}$ \\
\hline Mimulus nepalensis Benth. 물꽈리아재비 \\
\hline Pedicularis resupinata f. albiflora (Nakai) W. T. Lee 흰송이풀 \\
\hline Phtheirospermum japonicum (Thunb.) Kanitz 나도송이풀 \\
\hline $\begin{array}{l}\text { Pseudolysimachion rotundum var. subintegrum (Nakai) T. } \\
\text { Yamaz. 산꼬리풀 }\end{array}$ \\
\hline Scrophularia kakudensis Franch. 큰개현삼 \\
\hline Campanulaceae 초롱꽃과 \\
\hline Adenophora remotiflora (Siebold \& Zucc.) Miq. 모시대 \\
\hline Adenophora verticillata (Pall.) Fisch. 층층잔대 \\
\hline Asyneuma japonicum (Miq.) Briq. 영아자 \\
\hline Codonopsis lanceolata (Siebold \& Zucc.) Trautv. 더덕 \\
\hline Rubiaceae 꼭두선이과 \\
\hline Asperula lasiantha Nakai 갈퀴아재비 \\
\hline Asperula maximowiczii Kom. 개갈퀴 \\
\hline Asperula odorata $\mathrm{L}$. 선갈퀴 \\
\hline Galium dahuricum Turcz. 큰잎갈퀴 \\
\hline Galium paradoxum Maxim. 두메갈퀴 \\
\hline Galium pogonanthum Franch. \& Sav. 산갈퀴 \\
\hline Galium spurium var. echinospermum (Wallr.) Hayek 갈퀴덩굴 \\
\hline Paederia scandens (Lour.) Merr. 계요등 \\
\hline Rubia akane Nakai 꼭두선이 \\
\hline Rubia chinensis Regel \& Maack 큰꼭두선이 \\
\hline Rubia cordifolia var. pratensis Maxim. 갈퀴꼭두선이 \\
\hline Diervillaceae 병꽃나무과 \\
\hline Weigela florida (Bunge) A. DC. 붉은병꽃나무 \\
\hline Weigela subsessilis (Nakai) L. H. Bailey 병꽃나무 \\
\hline Caprifoliaceae 인동과 \\
\hline Lonicera harae Makino 길마가지나무 \\
\hline Lonicera japonica Thunb. 인동 \\
\hline Lonicera praeflorens Batalin 올괴불나무 \\
\hline Viburnaceae 산분꽃나무과 \\
\hline Viburnum dilatatum Thunb. 가막살나무 \\
\hline Viburnum opulus var. calvescens (Rehder) H.Hara 백당나무 \\
\hline Adoxaceae 연복초과 \\
\hline Sambucus sieboldiana var. miquelii (Nakai) H.Hara 지렁쿠나무 \\
\hline Valerianaceae 마타리과 \\
\hline Patrinia scabiosifolia Fisch. ex Trevir. 마타리 \\
\hline Patrinia villosa (Thunb.) Juss. 뚝갈 \\
\hline Valeriana fauriei Briq. 쥐오줌풀 \\
\hline Dipsacaceae 산토끼꽃과 \\
\hline Scabiosa tschiliensis Grning 솔체꽃 \\
\hline Asteraceae 국화과 \\
\hline Adenocaulon himalaicum Edgew. 멸가치 \\
\hline Ainsliaea acerifolia Sch.Bip. 단풍취 \\
\hline Ambrosia artemisiifolia L. 돼지풀 \\
\hline Artemisia capillaris Thunb. 사철쑥 \\
\hline Artemisia japonica Thunb. 제비쑥 \\
\hline Artemisia keiskeana Miq. 맑은대쑥 \\
\hline Artemisia princeps Pamp. 夹 \\
\hline Artemisia rubripes Nakai 덤불쑥 \\
\hline Artemisia stolonifera (Maxim.) Kom. 넓은잎외잎쑥 \\
\hline Aster ageratoides Turcz. 까실쑥부쟁이 \\
\hline Aster incisus Fisch. 가새쑥부쟁이 \\
\hline Aster meyendorfii (Regel \& Maack) Voss 개쑥부쟁이 \\
\hline Aster scaber Thunb. 참취 \\
\hline Aster tataricus L. f. 개미취 \\
\hline Atractylodes ovata (Thunb.) DC. 삽주 \\
\hline Bidens biternata (Lour.) Merr. \& Sherff 털도깨비바늘 \\
\hline Carduus crispus L. 지느러미엉겅퀴 \\
\hline
\end{tabular}

Carpesium abrotanoides L. 담배풀

Carpesium cernuum L. 좀담배풀

Carpesium triste var. manshuricum (Kitam.) Kitam. 두메담배풀 Cirsium chanroenicum Nakai 정영엉겅퀴

Cirsium japonicum Fisch ex DC. 엉겅퀴

Cirsium setidens (Dunn) Nakai 고려엉겅퀴

Conyza canadensis (L.) Cronquist 망초

Coreopsis lanceolata $\mathrm{L}$. 큰금계국

Cosmos bipinnatus Cav. 코스모스

Crepidiastrum chelidoniifolium (Makino) J. H. Pak \& Kawano 까치고들빼기

Crepidiastrum denticulatum (Houtt.) J. H. Pak \& Kawano 이고들 빼기

Crepidiastrum sonchifolium (Bunge) J. H. Pak \& Kawano 고들빼기

Dendranthema zawadskii var. latilobum (Maxim.) Kitam. 구절초

Erigeron annuus (L.) Pers. 개 망초

Eupatorium japonicum Thunb. 등골나물

Hemistepta lyrata Bunge 지칭개

Hieracium umbellata L. 조밥나물

Ixeridium dentatum (Thunb.) Tzvelev 씀바귀

Ixeris chinensis (Thunb.) Kitag. 노랑선씀바귀

Ixeris chinensis subsp. strigosa (H. Lév. \& Vaniot) Kitam. 선씀바귀

Lactuca indica f. indivisa (Makino) Hara 가는잎왕고들 빼기

Lactuca indica var. laciniata (Kuntze) H. Hara 왕고들 빼기

Lactuca raddeana Maxim. 산씀바귀

Lactuca triangulata Maxim. 두메고들빼기

Ligularia fischeri (Ledeb.) Turcz. 곰취

Parasenecio hastatus subsp. orientalis (Kitam.) H. Koyama 민박쥐나물

Picris hieracioides var. koreana (Kitam.) Kitam. 쇠서나물

Saussurea gracilis Maxim. 은분취

Saussurea grandifolia Maxim. 서덜취

Saussurea macrolepis (Nakai) Kitam. 각시서덜취

Serratula coronata subsp. insularis (Iljin) Kitam. 산비장이

Sigesbeckia glabrescens Makino 진득찰

Solidago virgaurea subsp. asiatica Kitam. ex H. Hara 미역취

Syneilesis palmata (Thunb.) Maxim. 우산나물

Synurus excelsus (Makino) Kitam. 큰수리취

Taraxacum officinale F. H. Wigg. 서양민들레

Youngia japonica (L.) DC. 뽀리뺑이

Araceae 천남성과

Arisaema amurense Maxim. 둥근잎천남성

Arisaema peninsulae Nakai 점박이천남성

Commelinaceae 닭의장풀과

Commelina communis L. 닭의장풀

Commelina coreana $\mathrm{H}$. Lév 좀닭의장풀

\section{Juncaceae 골풀과}

Juncus setchuensis var. effusoides Buchenau 푸른갯골풀

Juncus tenuis Willd. 길골풀

Luzula capitata (Miq.) Miq. ex Kom. in Hultén 꿩의밥

Cyperaceae 사초과

Carex alterniflora $\mathrm{Fr}$. 선사초

Carex breviculmis $\mathrm{R}$. Br. 청사초

Carex gifuensis Franch. 애기감둥사초

Carex hakonensis Franch. \& Sav. 애기바늘사초

Carex japonica Thunb. 개찌버리사초

Carex lanceolata Boott 그늘사초

Carex leiorhyncha C. A. Mey. 산괭이사초

Carex planiculmis Kom. 그늘흰사초

Carex polyschoena H. Lév. \& Vaniot 가지청사초

Carex sabynensis Less. ex Kunth 실청사초

Carex siderosticta Hance 대사초

Cyperus microiria Steud. 금방동사니

Fimbristylis dichotoma $($ L.) Vahl 하늘지기

Poaceae 화본과

Agropyron ciliare (Trin.) Franch. 속털개밀

Agropyron tsukushiense var. transiens (Hack.) Ohwi 개밀

Agrostis clavata var. nukabo Ohwi 겨이삭

Alopecurus aequalis var. amurensis (Kom.) Ohwi 뚝새풀

Arundinella hirta var. ciliata (Thunb.) Koidz. 털새
Calamagrostis arundinacea (L.) Roth 실새풀

Dactylis glomerata L. 오리새

Diarrhena fauriei (Hack.) Ohwi 광릉용수염풀

Diarrhena mandshurica Maxim. 껍질용수염풀

Digitaria sanguinalis (L.) Scop. 바랭이

Echinochloa crusgalli (L.) P. Beauv. 돌피

Eragrostis ferruginea (Thunb.) P. Beauv. 그령

Microstegium vimineum var. imberbe (Ness ex Steud.) Honda 큰듬성이삭새

Miscanthus sinensis Andersson 억새

Muhlenbergia japonica Steud. 쥐꼬리새

Oplismenus undulatifolius (Ard.) Roem. \& Schult. 주름조개풀

Oplismenus undulatifolius var. japonicus (Steud.) Koidz.

민주름조개풀

Panicum bisulcatum Thunb. 개기장

Paspalum thunbergii Kunth ex Steud. 참새피

Pennisetum alopecuroides (L.) Spreng. 수크령

Phragmites japonica Steud. 달뿌리풀

Poa acroleuca Steud. 실포아풀

Sasa borealis (Hack.) Makino \& Shibata 조릿대

Secale cereale L. 호밀

Setaria faberi R. A. W. Herrm. 가을강아지풀

Setaria glauca (L.) P. Beauv. 금강아지풀

Setaria viridis (L.) P. Beauv. 강아지풀

Spodipogon sibiricus Trin. 큰기름새

Stipa pekinensis Hance 나래새

Themeda triandra subsp. japonica (Willd.) T. Koyama 솔새

Trisetum sibiricum Rupr. 시베리아잠자리피

\section{Liliaceae 백합과}

Allium macrostemon Bunge 산달래

Allium thunbergii var. teretifolium H. J. Choi \& B. U. Oh 둥근산부추

Convallaria keiskei Miq. 은방울꽃

Disporum smilacinum A. Gray 애기나리

Disporum uniflorum Baker 윤판나물

Disporum viridescens (Maxim.) Nakai 큰애기나리

Heloniopsis koreana S. Fuse, N. S. Lee \& M. N. Tamura 처녀치마

Hemerocallis hakuunensis Nakai 백운산원추리

Hosta capitata (Koidz.) Nakai 일월비비추

Lilium amabile Palib. 털중나리

Lilium cernuum Kom. 솔나리

Lilium distichum Nakai ex Kamib. 말나리

Lilium tsingtauense Gilg 하늘 말나리

Liriope spicata (Thunb.) Lour. 개맥문동

Maianthemum bifolium (L.) F. W. Schmidt 두루미꽃

Maianthemum dilatatum (A. W. Wood) A. Nelson \& J. F.

Macbr. 큰두루미꽃

Paris verticillata M. Bieb. 삿갓나물

Polygonatum inflatum Kom. 퉁둥굴레

Polygonatum lasianthum Maxim. 죽대

Polygonatum odoratum var. pluriflorum (Miq.) Ohwi 둥굴레

Scilla scilloides (Lindl.) Druce 무릇

Smilacina japonica A. Gray 풀솜대

Veratrum patulum Loes. 박새

Veratrum versicolor $\mathrm{Nakai}$ 흰여로

Iridaceae 붓꽃과

Iris sanguinea Donn ex Hornem. 붓꽃

Smilacaceae 청미래덩굴과

Smilax china $\mathrm{L}$. 청미래덩굴

Smilax nipponica Miq. 선밀나물

Smilax riparia A. DC. 밀나물

Smilax sieboldii var. inermis (Nakai) H. Hara 민청가시덩굴

Smilax sieboldii Miq. 청가시덩굴

Streptopus ovalis (Ohwi) F. T .Wang \& Y. C .Tang 금강애기나리

Dioscoreaceae 마과

Dioscorea nipponica Makino 부채마

Ochidaceae 난초과

Amitostigma gracile (Blume) Schltr. 병아리난초

Cephalanthera erecta (Thunb.) Lindl. 은난초

Cephalanthera longibracteata Blume 은대난초

Gastrodia elata Blume 천마

Oreorchis patens (Lindl.) Lindl. 감자난초 